\title{
e-learning: access the ERS Copenhagen archives
}

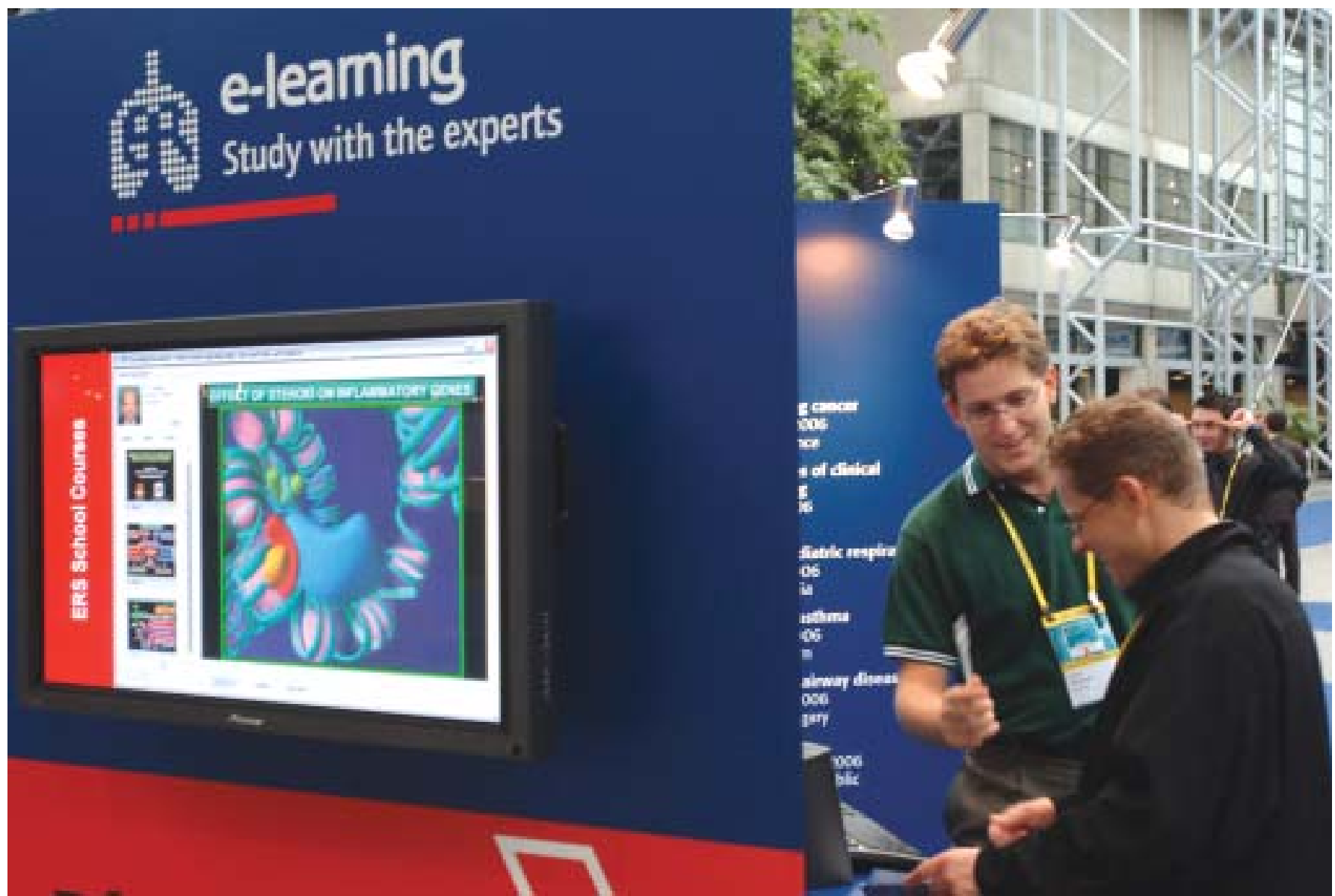

Every day during the ERS Annual Congress, over 80 invited speakers presented in Symposia, and $\sim 250$ original abstracts were presented in oral sessions. This year, to solve this problem and to make the decisions easier, all presentations are available on the ERS Learning resources website for the first time (www.ersnet.org/elearning). This facility provides ERS Members with access to all the material produced by the ERS during the Annual Congresses.

\section{The ERS Learning Resources}

One of the major beneficial features of this system is the ability to Browse and Search to retrieve information from the enormous range of original material available.

The new Learning Resources facility will allow better dissemination of Congress material. Participants of the Copenhagen Congress and those who were unable to attend will be able to retrieve 


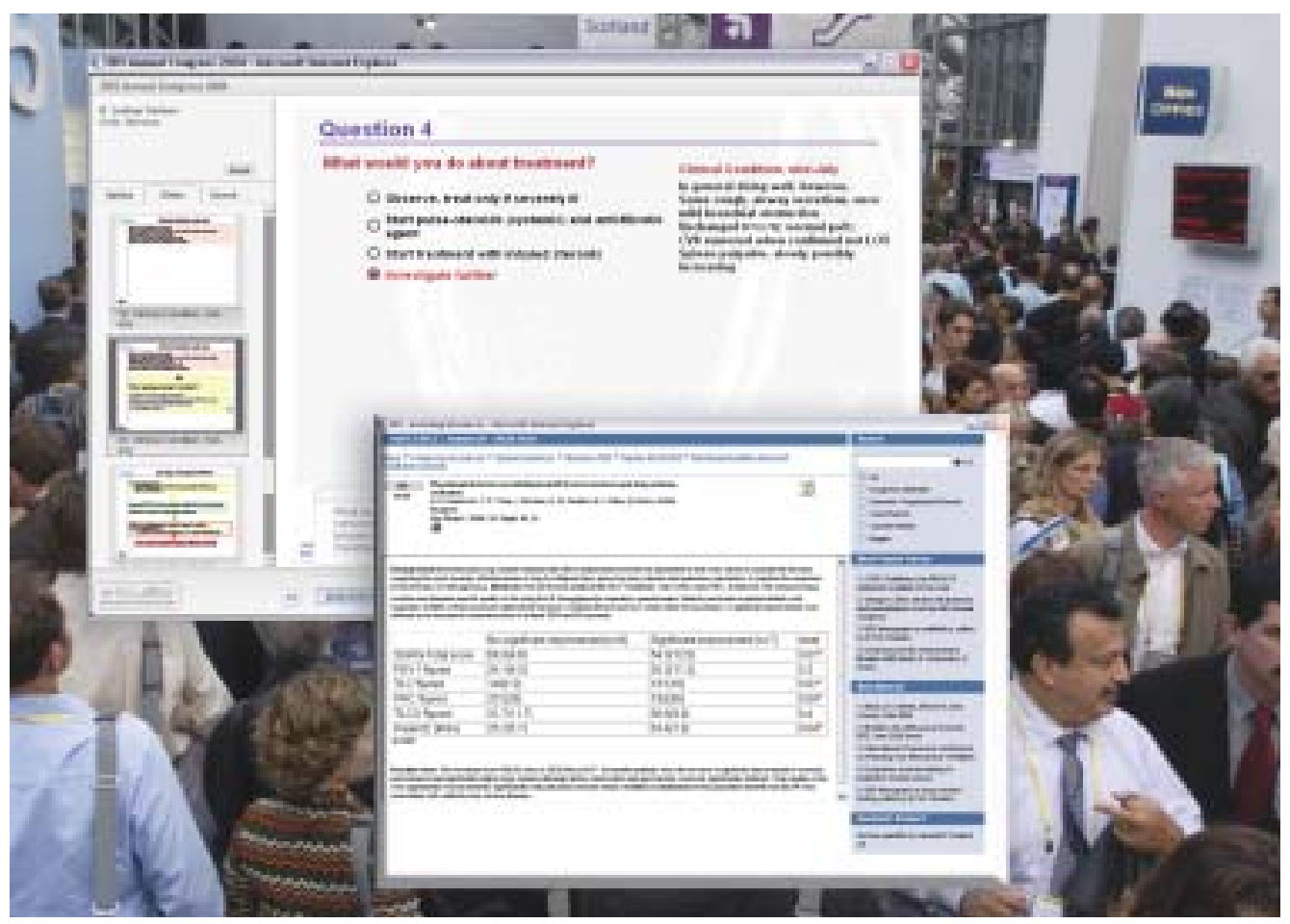

$>700$ original PowerPoint presentations that were prepared specifically for this meeting. Handouts from the Saturday PG Courses are also available to download in PDF format. Additionally, all of the abstracts from the Copenhagen Congress and all Annual Congresses since 1999 can be searched and retrieved.

Currently available:

- 64,431 slides

- 2,003 PowerPoint presentations

- 70 hours of web casts

- Handouts from School courses

- 17,560 Congress abstracts

- Access to 6,192 ERJ articles

- Guidelines

- Image database

- Breathe

- Monograph

\section{Centralised access to ERS publications}

In addition to Congress and Course material, the Learning Resources also offer centralised access to the ERS publications, including the European Respiratory Journal (ERJ), the Monograph and Breathe. For each ERJ article, the abstract and bibliographic references are available in Medline format for easy search. Full articles (in HTML or PDF) can be downloaded from the HighWire ERJ website (www.erj.ersjournals.com), which also has many other interesting features, including the ability to use cross-referencing.

\section{Image database}

Images are very useful material, both for teaching and self-learning. In 2004, the ERS School awarded an Educational Research grant to Mike Roberts (London, UK) to develop an interactive image database. The first of these images are now available in the Learning Resources. Each picture is accompanied by educational questions for selfassessment. This new feature is currently under evaluation and we would appreciate it if our Members could answer a couple of questions regarding their educational needs in order to help with our assessment.

In contrast to other medical societies, the ERS wishes to make knowledge and best practice accessible to all respiratory professionals, regardless of their financial resources. Therefore, these Learning Resources are freely available to all Members. With the new ERS policy on low-income countries making membership more obtainable for more people, access to the most recent and relevant sources of information is becoming possible for respiratory professionals everywhere. For a free tour of the new Learning Resources, visit www.ersnet.org/elearning

For more information or if you have any questions, please contact elearning@ersnet.org.
Respecting authors' work The material provided by the authors and speakers is made freely available to a large community of respiratory specialists. Copyright remains the exclusive property of the authors, and the ERS only has permission to disseminate this educational material through its website. Slides and presentations can be used for your own educational needs. However, if you wish to use some material in presentations, we urge you to get the explicit permission from the authors. By doing so, you will be respecting your colleagues' work and giving appropriate credit to your peers. 